(C) 2017 by the Arizona Board of Regents on behalf of the University of Arizona. This is an Open Access article, distributed under the terms of the Creative Commons Attribution licence (http://creativecommons. org/licenses/by/4.0/), which permits unrestricted re-use, distribution, and reproduction in any medium, provided the original work is properly cited.

\title{
STABLE CARBON ISOTOPIC COMPOSITION IN ANNUAL RINGS OF A PINE TREE (PINUS DENSIFLORA) FROM YEONGWOL, KOREA: POSSIBLE APPLICATION TO CLIMATE STUDY
}

\author{
Chi-Hwan $\mathrm{Kim}^{1 *} \cdot \operatorname{Jang}$ Hoon Lee ${ }^{1} \cdot \mathrm{Jin} \mathrm{Kang}^{1} \cdot$ Sujin Song $^{1} \bullet$ Myung-ho Yun ${ }^{1} \bullet$ \\ Jong Chan $\mathrm{Kim}^{2}$ \\ ${ }^{1}$ National Center for Inter-University Research Facilities, Seoul National University, Seoul 151-742 Korea. \\ ${ }^{2}$ Department of Physics and Astronomy, Seoul National University, Seoul 151-747 Korea.
}

\begin{abstract}
Stable carbon isotope ratios were measured on the alpha-cellulose in tree rings of a pine tree (Pinus densiflora) from Yeongwol, Korea. We developed an annual-resolution $\delta^{13} \mathrm{C}$ series (1835-1905) by correcting the measured data for changes in $\delta^{13} \mathrm{C}$ of air to minimize non-climatic influences. To investigate the climatic signal in the $\delta^{13} \mathrm{C}$ series, we performed correlation analysis between $\delta^{13} \mathrm{C}$ and the Cheugugi climate data. The Cheugugi precipitation data were first recorded by King Sejong (1397-1450) of the Joseon Dynasty. However, the longest set of precipitation data available is the one collected in Seoul (1776-1907). Although many studies support the reliability of the Cheugugi data, no previous studies have investigated the potential of the $\delta^{13} \mathrm{C}$ signal in tree rings as paleoclimate proxy using the Cheugugi data. Recent precipitation trends in Yeongwol are quite similar to that of Seoul, and we found significant correlations between the Cheugugi data and the $\delta^{13} \mathrm{C}$ series. We suggest further studies to replicate these results and confirm whether comparing $\delta^{13} \mathrm{C}$ variations in tree rings and Cheugugi data is a useful method of investigating the potential of the $\delta^{13} \mathrm{C}$ signal as a paleoclimate proxy in or near the Korean peninsula.
\end{abstract}

KEYWORDS: tree ring, carbon isotope, Cheugugi data, correlation.

\section{INTRODUCTION}

Climate change is currently an issue of scientific and political importance. To understand climate change, reconstructions of past climate variations are essential. Natural archives (such as tree rings, ice cores, and corals) are useful for reconstructing past climatic conditions and compensate for the lack of meteorological measurements (McCarroll and Loader 2004; Sano et al. 2009). In particular, the variation of carbon isotope composition in annual tree rings, with their high time resolution, can play an important role in climate reconstructions. The concentrations of radiocarbon $\left({ }^{14} \mathrm{C}\right)$ and light stable isotopes $\left({ }^{2} \mathrm{H},{ }^{13} \mathrm{C},{ }^{18} \mathrm{O}\right.$, etc. $)$ in annual rings are sensitive indicators of climate variables (such as temperature, precipitation, and insolation), but also reflect anthropogenic influences (McCarroll and Loader 2004; Pazdur et al. 2007).

On the other hand, historical climate data are also useful for reconstructing past climatic conditions. Cheugugi (meaning "rain-measuring device") data are one such set of historical climate data for the Korean peninsula. They were first recorded by King Sejong (1397-1450) of the Joseon Dynasty. However, the longest set of precipitation data available is the one collected in Seoul AD 1777-1907. The main structure of the Cheugugi data is unique, containing the start time, end time, and total amount of rain during each event (Yoo et al. 2015). Therefore, the duration and total amount of rain during each rainfall event are available. Many studies have found long-term correlations between the Cheugugi data and climate-related data, such as the Southern Oscillation Index, and have claimed that such correlations are evidence of the reliability of the Cheugugi data (Hwang et al. 2009; Kim et al. 2010). Recently, Jung et al. (2001) found statistical similarities between the Cheugugi data and modern precipitation data, and suggested the Cheugugi data are reliable for short-term (diurnal) precipitation study.

\footnotetext{
*Corresponding author. Email: child7@snu.ac.kr.
} 
However, although many studies support the reliability of the Cheugugi data, studies have not investigated the potential of the $\delta^{13} \mathrm{C}$ signal in tree rings as paleoclimate proxy using the Cheugugi data. To perform such studies, tree rings that are expected to contain the precipitation information of the Cheugugi data should be identified and analyzed. For example, tree rings should be selected that formed in the period of the precipitation record and also in the region near the measurement station. However, such tree-ring samples are not easy to obtain in Korea for several reasons (such as city or residents' approval).

We recently obtained tree-ring samples from a pine tree stump (Pinus densiflora) located at Yeongwol, Korea, approximately $100 \mathrm{~km}$ east from Seoul, Korea, where the longest Cheugugi data were recorded. Recent 21-yr precipitation trends in Yeongwol are quite similar to Seoul, so we expected precipitation variations from the Cheugugi data would be reflected in $\delta^{13} \mathrm{C}$ in the tree rings, and found significant correlations between the Cheugugi data and $\delta^{13} \mathrm{C}$ data. We suggest further studies to replicate these results and confirm whether comparing $\delta^{13} \mathrm{C}$ variations in tree rings and Cheugugi data is a useful method of investigating the potential of the $\delta^{13} \mathrm{C}$ signal as a paleoclimate proxy in or near the Korean peninsula.

\section{THE YEONGWOL PINE TREE AND ITS GROWING AREA}

The pine tree (Pinus densiflora) was located in Seoun Old Pine Tree Park $\left(37^{\circ} 22^{\prime} 19^{\prime \prime} \mathrm{N}\right.$, $128^{\circ} 11^{\prime} 19^{\prime \prime}$ E), Suju-myeon, Yeongwol-gun, Gangwon-do in South Korea, as shown in Figure 1a. The tree itself, shown in Figure 1b, was listed as a protected tree by Yeongwol County Government, was $20 \mathrm{~m}$ high with $3.7 \mathrm{~m}$ circumference, and was considered a "protector" of the village. However, the tree was knocked down by wind in March 2010. Now, only the stump of the tree remains, as shown in Figure 1c.

Meteorological data from the Yeongwol station $\left(37^{\circ} 10^{\prime} 52.421^{\prime \prime} \mathrm{N}, 128^{\circ} 27^{\prime} 26.930^{\prime \prime} \mathrm{E}\right.$, records started 1995), which is located approximately $30 \mathrm{~km}$ from the sample site, were used to assess the climate at the sample site. Over the 1995-2015 period, mean annual temperature was $11^{\circ} \mathrm{C}$, mean number of annual days with precipitation was 113, and mean annual precipitation was $1231 \mathrm{~mm}$ (with ca. 71\% occurring during June-September) (KMA 2016). To investigate the climate similarity between Yeongwol and Seoul (where the Cheugugi data used in this study were recorded), we compared meteorological data from the Seoul station $\left(37^{\circ} 34^{\prime} 17^{\prime \prime} \mathrm{N}, 126^{\circ} 57^{\prime} 56^{\prime \prime} \mathrm{E}\right.$, modern records started 1907) and that from the Yeongwol station over years with overlapping records (1995-2015). As shown in Figure 2, the average monthly (annual) precipitation and temperature patterns of the two stations are quite similar. Correlations between the data of the two stations are $0.644,0.604$, and 0.777 for annual temperature, precipitation, and number of precipitation days, respectively ( $p<0.01$ in all cases). Therefore, we may assume that climate changes (particularly precipitation) at Seoul were similar to that at Yeongwol during the Cheugugi data recording period. Based on this assumption, we used the Cheugugi data recorded at Seoul to investigate the potential of $\delta^{13} \mathrm{C}$ in tree-ring samples from Yeongwol as a paleoclimate proxy.

\section{SAMPLE COLLECTION AND DENDROCHRONOLOGICAL DATING}

A radial slice (ca. $12 \mathrm{~cm}$ ) was cut from the upper part of the stump, about $1.0 \mathrm{~m}$ above ground level. Based on radiocarbon $\left({ }^{14} \mathrm{C}\right)$ dating using the wiggle-matching method, the age of the pine tree was estimated to be at least $211 \mathrm{yr}$ (Kim et al. 2015). However, at the time of sampling (2014), many parts of the stump were decayed, so we could not collect all tree rings in the stump, as shown in Figure 1c.

Tree-ring samples were dated at the Tree-Ring Material Bank of Chungbuk National University using the dendrochronological method (Rinn 1996). Ring-width plots (0.01 mm 

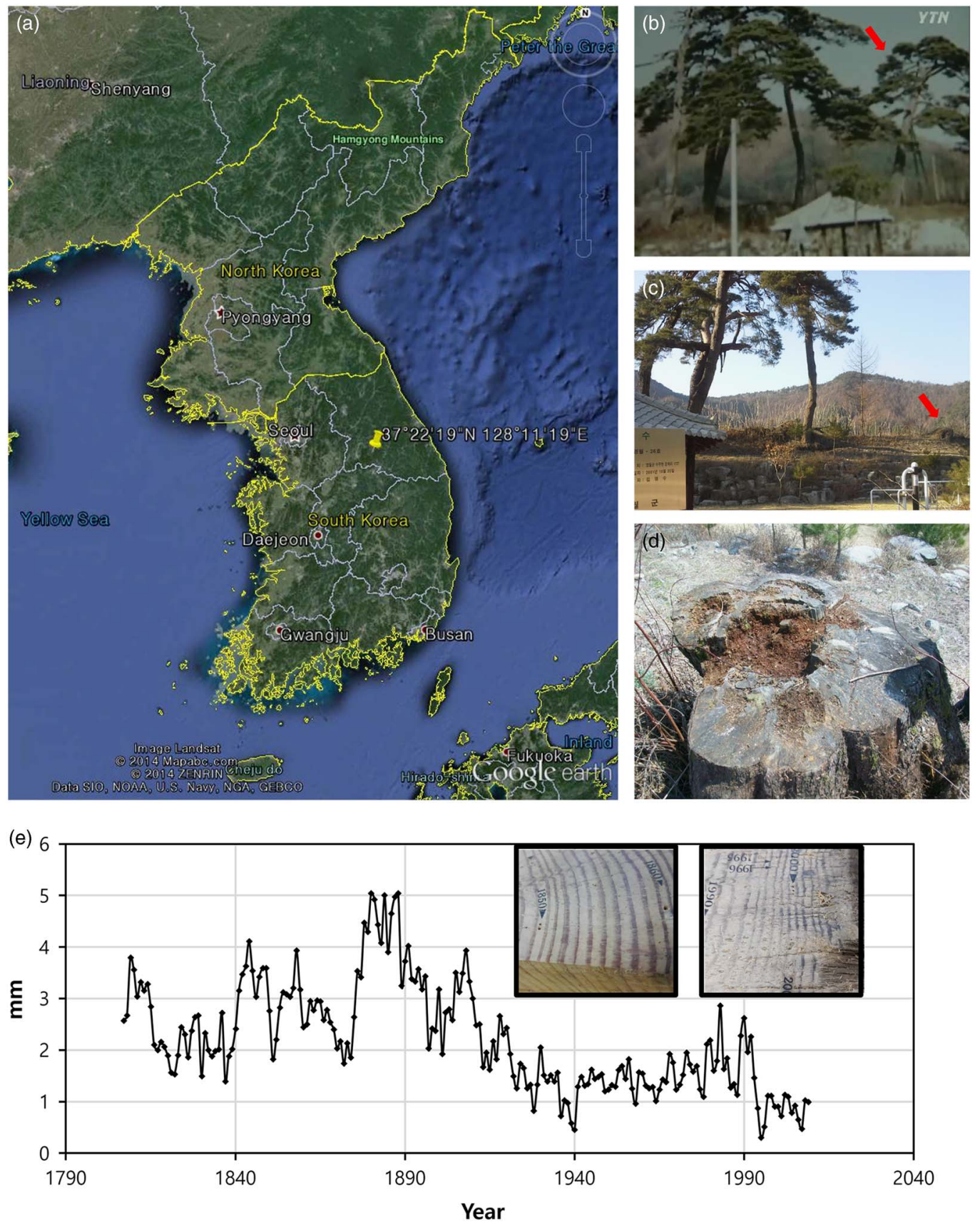

Figure 1 Yeongwol pine tree: (a) location image adapted from Google Earth (2014); (b) before (YTN 2010) and (c) after the wind event in March 2010 (indicated by arrow); (d) remaining stump (2014); and (e) tree-ring width plot and examples of dendrochronologically dated tree-ring samples.

precision) of the tree-ring samples were crossdated by matching their patterns with master chronologies that had been absolutely dated through matches with living trees. The master chronologies used were GRAND PI (1657-1999) and HGGPD (1906-2011). The calculated 
(a)
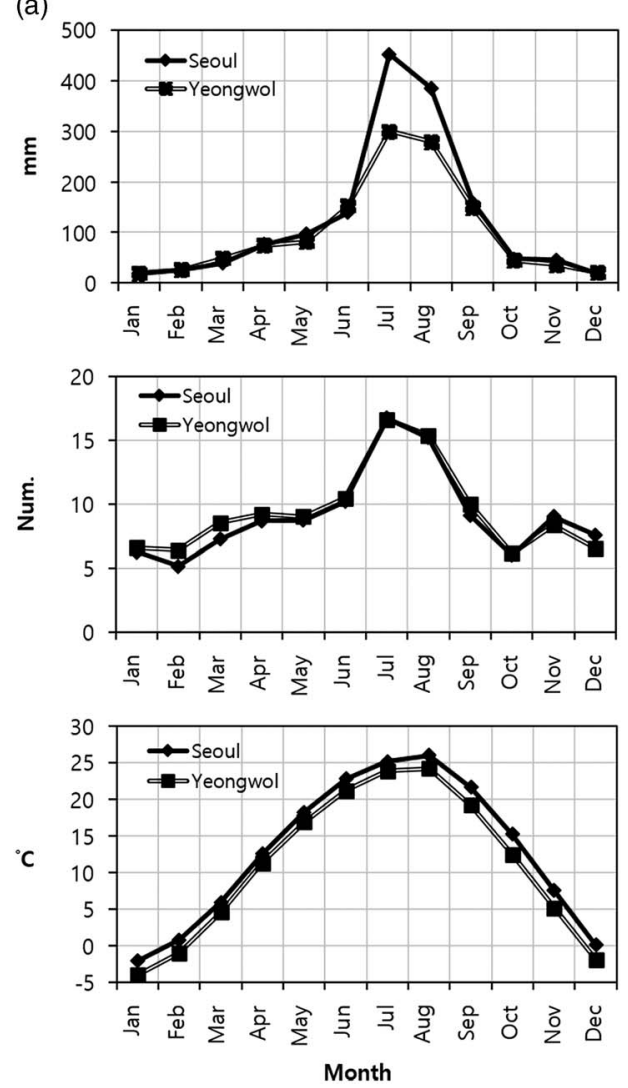

(b)
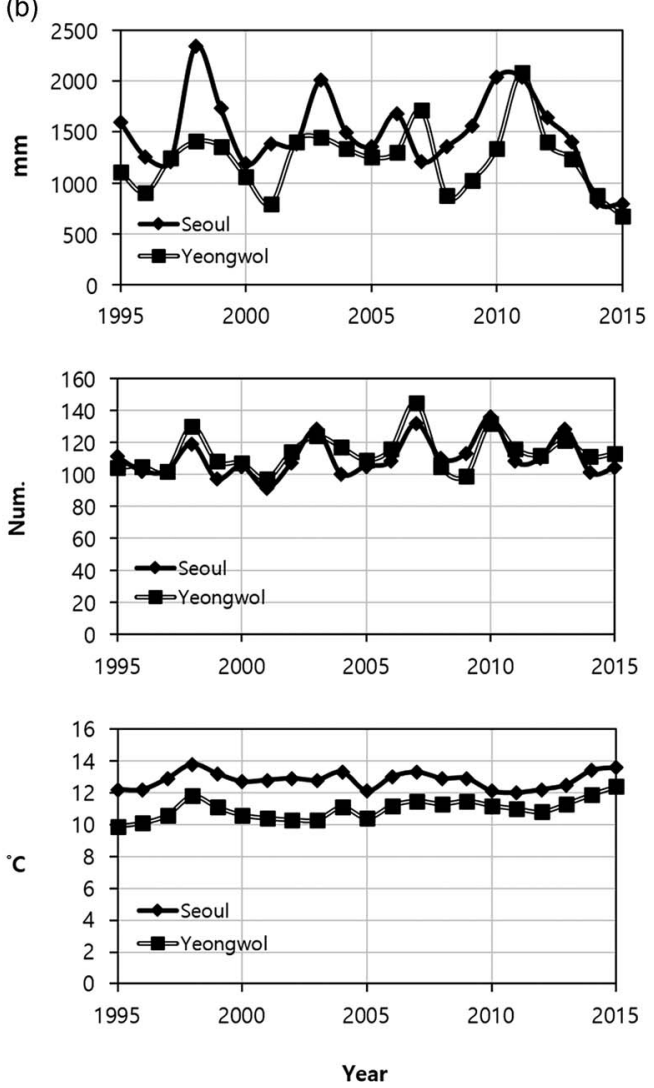

Figure 2 (a) Monthly average precipitation (number of precipitation days, temperature) for 1995-2015 at Yeongwol and Seoul; (b) annual variation of precipitation (number of precipitation days, temperature) 1995-2015 at Yeongwol and at Seoul.

$t$-values were 4.7 and 3.3 for GRAND PI and HGGPD, respectively. The tree rings dated to AD 1807 to AD 2009.

\section{SAMPLE PREPARATION AND EXPERIMENT}

As shown in Figure 1e, although dendrochronological dating was accomplished, some rings in the period 1900-2009 were rotten and it was not feasible to attempt to separate annual rings. Therefore, tree rings after 1905 were excluded from this study. More detailed and systematic work using modern precipitation data will be left for future studies. Since tree rings near the center of the stump were estimated older than 1802, we also excluded tree rings before 1835 , to avoid possible juvenile effects (Leavitt 2010). Ultimately, we selected tree rings from the 1835-1905 interval, which is within the period of recorded Cheugugi data, and focused on comparing the Cheugugi data and $\delta^{13} \mathrm{C}$ series.

Samples with known ages were cut into annual rings and treated by the alpha cellulose extraction method described in Park et al. (2010). Each wood sample was immersed in $0.5 \mathrm{M}$ of $\mathrm{HCl}$ at $80-85^{\circ} \mathrm{C}$ for $30 \mathrm{~min}$ then washed to neutral $\mathrm{pH}$. The samples were then subjected to $0.1 \mathrm{M}$ of $\mathrm{NaOH}$ at $80-85^{\circ} \mathrm{C}$ for $1 \mathrm{hr}$ and then washed to a neutral $\mathrm{pH}$. They were treated by applying $4 \% \mathrm{NaClO}_{2}$ at $55-60^{\circ} \mathrm{C}$ for $1 \mathrm{hr}$ to extract $\alpha$-cellulose then washed to neutral $\mathrm{pH}$. They were again 
immersed in $0.5 \mathrm{M}$ of $\mathrm{HCl}$ at $80-85^{\circ} \mathrm{C}$ for $30 \mathrm{~min}$ to remove any $\mathrm{CO}_{2}$ absorbed during the second and third steps, and then washed to neutral $\mathrm{pH}$. Residues were dried at $120^{\circ} \mathrm{C}$ for $8 \mathrm{~h}$.

The dried samples $(0.7-1 \mathrm{mg})$ were loaded into tin capsules and placed in the elemental analyzer (vario PYRD cube, Elementar, Germany) auto-sampler. Stable carbon isotope content was determined using continuous flow isotope ratio mass spectrometry (Vision, Isoprime, Manchester, UK) attached to the elemental analyzer. IAEA-CH-6 was used as a reference material. IAEA-C6 was measured after every 10 experimental samples to monitor mass-spectrometer stability. The average precision on replicate results was ca. $0.27 \%$, which reflects sample preparation and measurement errors. The value of the carbon isotope ratios was obtained as an average of the duplicate analyses on an annual tree-ring cellulose sample. In the end, we developed an annual-resolution $\delta^{13} \mathrm{C}$ (PDB standard) series of $1835-1905$ by using the measured data.

\section{DATA ANALYSIS}

Several studies have reported that the tree-ring $\delta^{13} \mathrm{C}$ series generally shows a downward trend starting around $\mathrm{AD} 1800-1850$, resulting from ${ }^{13} \mathrm{C}$-depleted $\mathrm{CO}_{2}$ emissions from fossil fuel combustion changing the isotopic composition of the atmosphere. In addition to this effect, there are changes in plant response as a consequence of increasing atmospheric $\mathrm{CO}_{2}$ concentrations (McCarroll and Loader 2004; McCarroll et al. 2009). Hence, $\delta^{13} \mathrm{C}$ values were corrected for changes in air $\delta^{13} \mathrm{C}$ to minimize non-climatic influences. $\delta^{13} \mathrm{C}$ values were corrected first to remove the atmospheric decline in the $\delta^{13} \mathrm{C}$ values of atmospheric $\mathrm{CO}_{2}$, by simple addition using the values provided by McCarroll and Loader (2004), and then for changes in the response to the rising $\mathrm{CO}_{2}$ content of the atmosphere using the pre-industrial (PIN) correction proposed by McCarroll et al. (2009). Then, we investigated the correlation between corrected $\delta^{13} \mathrm{C}$ and Cheugugi rainfall data. We used monthly precipitation data and number of rainy days obtained from the Cheugugi data (Wada 1917; KMA 2011) for correlation analysis. We used 'PIN' R package (ver. 0.6, Swansea University) for $\delta^{13} \mathrm{C}$ correction and SPSS (ver. 22) for statistical analysis.

\section{EXPERIMENTAL RESULTS}

Figure 3 a shows the raw and corrected $\delta^{13} \mathrm{C}$ series $\left(\delta^{13} \mathrm{C}_{\text {raw }}\right.$ and $\delta^{13} \mathrm{C}_{\text {pin }}$, respectively) of our tree-ring samples. Both $\delta^{13} \mathrm{C}$ profiles are within the range -26.3 to $-23.4 \%$, which is comparable with the results of other studies of Pinus densiflora (Park et al. 2002; Choi et al. 2005; Hong et al. 2013). Climatic records used for comparison were monthly total precipitation and number of precipitation days obtained from the Cheugugi data. The precipitation trends recorded in the Cheugugi data over the period overlapping with the period of our $\delta^{13} \mathrm{C}$ chronologies (1835-1905) are illustrated in Figures $3 \mathrm{~b}$ and $3 \mathrm{c}$. The mean number of annual precipitation days was 64 days and the mean annual precipitation was $1132 \mathrm{~mm}$ (with ca. $74 \%$ occurring during June-September) during the observation period. It should be mentioned that the Cheugugi data do not include frozen precipitation (ca. $40 \mathrm{~mm} / \mathrm{yr}$ ) and precipitation events below ca. $2 \mathrm{~mm}$ (ca. 35-40 mm/yr). The sum of these is ca. $75-80 \mathrm{~mm} / \mathrm{yr}$ (Jung et al. 2001).

The growing season of conifer tree species in Korea is typically from April to September (Kim and Park 2011). Therefore, we investigated correlations with monthly precipitation during AD 1835-1905 from October of the previous year to September of the year of ring formation. Since the Cheugugi data do not contain precipitation as snow, we excluded the data recorded during the winter season (December-February) for analysis.

Figure 4 a shows the correlation coefficients between the $\delta^{13} \mathrm{C}$ series and monthly precipitation. There are no significant correlations with monthly precipitation for $\delta^{13} C_{\text {raw }}$. However, when 


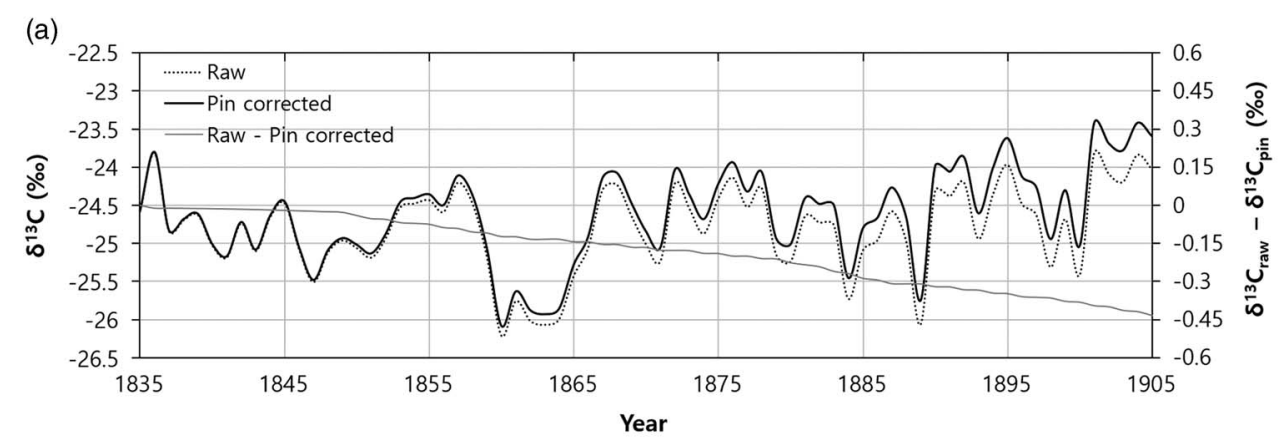

(b)

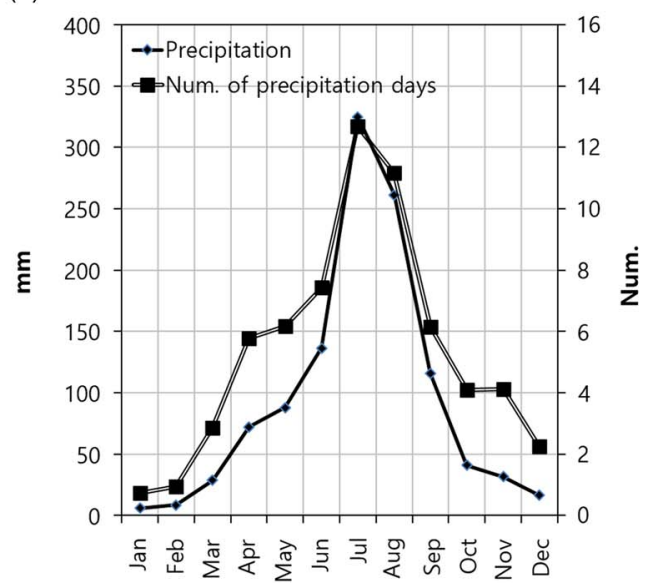

(c)
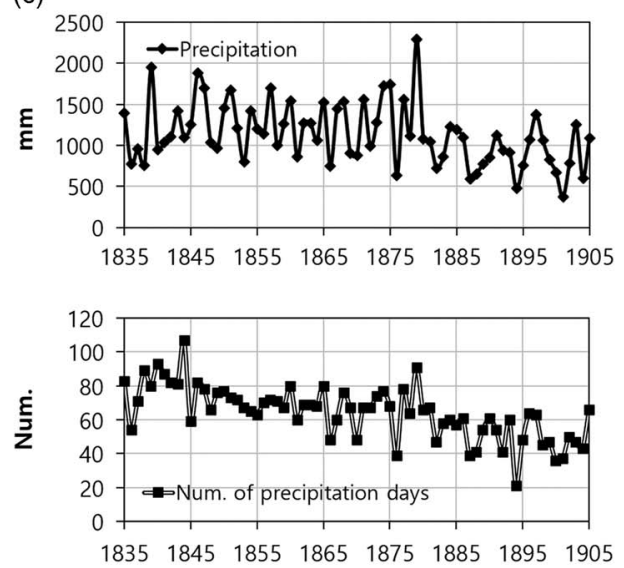

Figure 3 (a) Corrections to the $\delta^{13} \mathrm{C}$ chronology: the dotted line represents raw $\delta^{13} \mathrm{C}\left(\delta^{13} \mathrm{C}_{\text {raw }}\right)$ and the solid line represents corrected $\delta^{13} \mathrm{C}\left(\delta^{13} \mathrm{C}_{\text {pin }}\right)$. Cheuguigi data overlapping with the $\delta^{13} \mathrm{C}$ chronologies (1835-1905): (b) monthly average of precipitation (number of precipitation days); and (c) annual variation of precipitation (number of precipitation days).

combined, a significant negative correlation was found for July-September $(-0.292 ; p<0.05)$. For $\delta^{13} \mathrm{C}_{\mathrm{pin}}$, significant negative correlation was found with July $(-0.251, p<0.05)$ and, when combined, the highest correlation was found for July-September $(-0.332 ; p<0.01)$. Figure $4 \mathrm{a}$ shows that the simple linear regression of $\delta^{13} \mathrm{C}_{\text {pin }}$ with precipitation July-September gives, $R^{2}=0.110$ and slope $=-6.44 \times 10^{-4} \% / \mathrm{mm}$.

Figure $4 \mathrm{~b}$ shows the correlation coefficients between the $\delta^{13} \mathrm{C}$ series and the monthly number of precipitation days. There are significant negative correlations for $\delta^{13} C_{\text {raw }}$ with July $(-0.324$, $p<0.01)$ and August $(-0.290, p<0.05)$. When combined, the highest correlation was found for July-September $(-0.422 ; p<0.01)$. There are significant negative correlations for $\delta^{13} \mathrm{C}_{\text {pin }}$ with July $(-0.386, p<0.01)$, August $(-0.346, p<0.01)$, and September $(-0.263, p<0.05)$. When combined, the highest correlation found was for July-September $(-0.501 ; p<0.01)$. Figure $4 \mathrm{~b}$ shows that the simple linear regression of $\delta^{13} \mathrm{C}_{\text {pin }}$ with the number of precipitation days July-September gives, $R^{2}=0.255$ and slope $=-0.036 \% /$ num.

\section{DISCUSSION AND CONCLUSION}

There are well-known mechanisms for $\delta^{13} \mathrm{C}$ variation in $\mathrm{C}_{3}$ plants (Francey and Farquhar 1982; Farquhar et al. 1989; Marshall and Monserud 1996), which may explain the correlations 
(a)
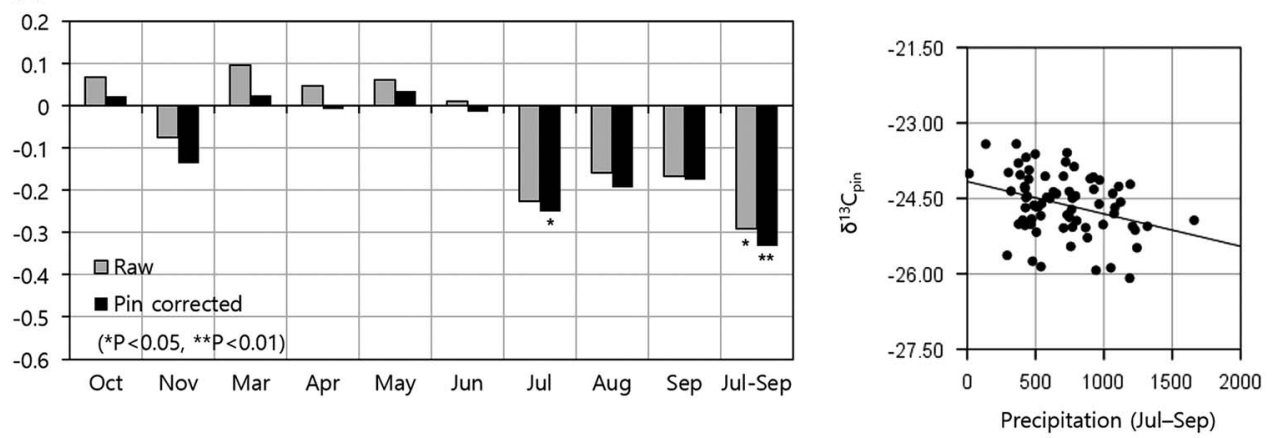

(b)
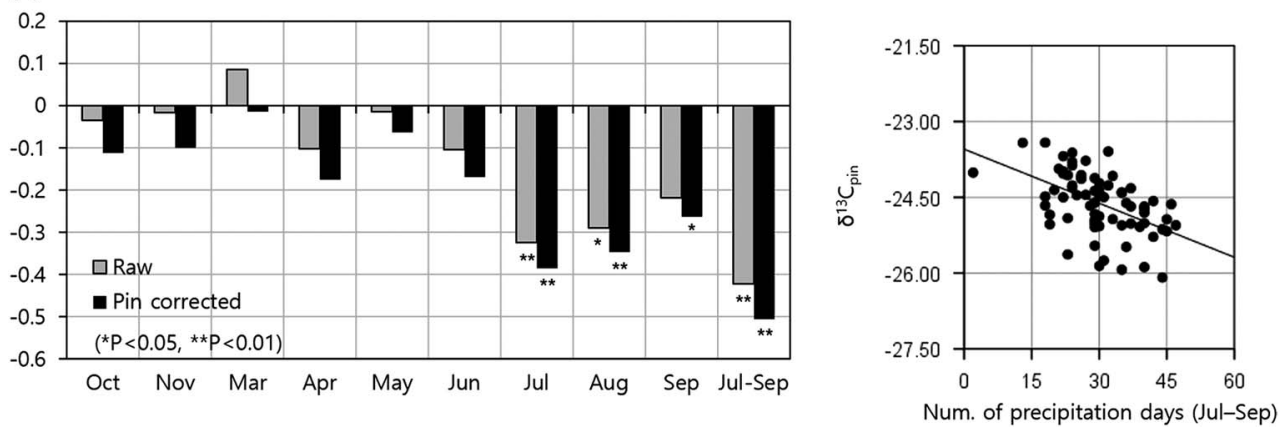

Figure 4 Pearson correlation coefficients between the $\delta^{13} \mathrm{C}$ series $\left(\delta^{13} \mathrm{C}_{\text {raw }}\right.$ and $\left.\delta^{13} \mathrm{C}_{\text {pin }}\right)$ and monthly climatic variables: (a) precipitation, (b) number of precipitation days.

observed in this study. Carbon stored in tree-ring cellulose is produced using $\mathrm{CO}_{2}$ taken up by the leaves and the $\mathrm{C}_{3}$ photosynthetic pathway preferentially uses ${ }^{12} \mathrm{C}$, leading to isotopically depleted tree-ring cellulose. Therefore, $\mathrm{CO}_{2}$ concentration decrease in stomatal chambers can increase the ${ }^{13} \mathrm{C}^{12} \mathrm{C}$ ratio of tree-ring cellulose. The balance between the rate at which $\mathrm{CO}_{2}$ enters, by stomatal conductance, and the rate at which it is removed, by photosynthesis, can explain the variation of $\mathrm{CO}_{2}$ concentration in stomatal chambers. For example, the increased $\delta^{13} \mathrm{C}$ reflects decreased $\mathrm{CO}_{2}$ concentration in stomatal chambers, which may be due to either decreased stomatal conductance or increased photosynthetic rate, or some combination of the two. Hence, the observed negative correlations of $\delta^{13} \mathrm{C}$ with precipitation or the number of precipitation days may be explained by stomatal conductance, which can be negatively affected by moisture stress, or by photosynthesis, which can be positively affected by photon flux (sunlight) or temperature. On the other hand, in arid regions, where trees suffer from moisture stress, stomatal conductance may play a more important role in ${ }^{13} \mathrm{C}$ fractionation, leading to statistically significant relationships with antecedent or growing-season moisture supply. Where water stress is low, the photosynthetic rate should dominate, and annual $\delta^{13} \mathrm{C}$ is likely to correlate with measured climate variables such as sunshine, cloud cover, and temperature (McCarroll and Loader 2001). Hence, sufficient precipitation during the growing season in Yeongwol (Figure 2), may be one of the reasons why $\delta^{13} \mathrm{C}$ was more negatively correlated with the number of precipitation days than the precipitation amounts. Accuracy of precipitation measurement, may be another reason for reduced correlations between $\delta^{13} \mathrm{C}$ and precipitation. 
Whatever the actual mechanism of the observed response, it is clear that some correlations (Figure 4) are large enough to be taken as meaningful. Although it is tempting to state that the climate signal of $\delta^{13} \mathrm{C}$ in tree rings was successfully demonstrated using the Cheugugi data, replication of initial results in this study is required to confirm our initial results. This may be necessary because results from an individual tree may not be fully representative of a site, and hence results from several trees should be combined to better extract reliable climate signals. On the other hand, some studies have reported examples of $\delta^{13} \mathrm{C}$ series from single cores that had remarkably strong correlations to climate, which is promising for studies involving rare and limited samples from archaeological or geological contexts (Liu et al. 2010). Consequently, we suggest further studies to replicate our initial results and confirm whether comparing $\delta^{13} \mathrm{C}$ variations in tree rings and Cheugugi data is a useful method for investigating the potential of the $\delta^{13} \mathrm{C}$ signal as a paleoclimate proxy in or near the Korean peninsula.

\section{ACKNOWLEDGMENTS}

We especially thank Prof. Danny McCarroll (Swansea University), Dr. Giles Young (Swansea University), and other members of their research group for providing the 'PIN' R package (ver. 0.6). This work was supported by the National Research Foundation of Korea (NRF) grant funded by the Korean government (MSIP) (No. 2015065241).

\section{REFERENCES}

Choi W, Lee S, Chang SX, Ro H. 2005. Variations of $\delta^{13} \mathrm{C}$ and $\delta^{15} \mathrm{~N}$ in Pinus Densiflora tree-rings and their relationship to environmental changes in eastern Korea. Water, Air, and Soil Pollution 164:173-87.

Francey RJ, Farquhar GD. 1982. An explanation of ${ }^{13} \mathrm{C} /{ }^{12} \mathrm{C}$ variations in tree rings. Nature 297:28-31.

Farquhar GD, Ehleringer JR, Hubick KT. 1989. Carbon isotope discrimination and photosynthesis. Annual Review of Plant Physiology and Plant Molecular Biology 40:503-37.

Hong W, Park JH, Park G, Sung KS, Park WK, Lee J. 2013. Regional offset of radiocarbon concentration and its variation in the Korean atmosphere from AD 1650-1850. Radiocarbon 55(2-3): 753-62.

Hwang SH, Kim JH, Yoo C, Chung G. 2009. Synoptic change characteristics of the east Asia climate appeared in Seoul rainfall and climatic index data. Journal of the Korean Society of Civil Engineers B 29(5B):409-17.

Jung HS, Lim GH, Oh JH. 2001. Interpretation of the transient variations in the time series of precipitation amounts in Seoul, Korea: Part 1. diurnal variation. Journal of Climate 14(13): 2989-3004.

Kim CH, Lee JH, Kang J, Song S, Yun MH, Kim JC. 2015. Radiocarbon dating of a pine tree (Pinus densiflora) from Yeongwol, Korea. Nuclear Instruments and Methods in Physics Research B 361:332-4.

Kim CJ, Weihong Q, Kang HS, Lee DK. 2010. Interdecadal variability of East Asian summer monsoon precipitation over 220 years (1777-1997). Advances in Atmospheric Sciences 27:253-64.
Kim YJ, Park WK. 2011. Dendrochronology. Hangang Journal of Archaeology 6:21-42.

KMA (Korea Meteorological Administration). 2011. Planning for recovery of the historical weather and climate information using Joseon Dynasty Archives. Seoul.

KMA (Korea Meteorological Administration). 2016. National Climate Data Service System, Republic of Korea. URL: <http://sts.kma.go.kr>.

Leavitt SW. 2010. Tree-ring $\mathrm{C}-\mathrm{H}-\mathrm{O}$ isotope variability and sampling. Science of the Total Environment 408:5244-53.

Liu Y, Wang R, Leavitt SW, Song H, Linderholm HW, Li Q, An Z. 2010. Individual and pooled tree-ring stable-carbon isotope series in Chinese pine from the Nan Wutai region, China: common signal and climate relationships. Chemical Geology 330-331:17-26.

Marshall JD, Monserud RA. 1996. Homeostatic gasexchange parameters inferred from ${ }^{13} \mathrm{C} /{ }^{12} \mathrm{C}$ in tree rings of conifers. Oecologia 105:13-21.

McCarroll D, Loader NJ. 2001. Stable carbon isotope ratios of Pinus sylvestris from northern Finland and the potential for extracting a climate signal from long Fennoscandian chronologies. The Holocene 11:517-26.

McCarroll D, Loader NJ. 2004. Stable isotopes in tree rings. Quaternary Science Reviews 23:771-801.

McCarroll D, Gagen MH, Loader NJ, Robertson I, Anchukaitis KJ, Los S, Young GHF, Jalkanen R, Kirchhefer A, Waterhouse JS. 2009. Correction of tree ring stable carbon isotope chronologies for changes in the carbon dioxide content of the atmosphere. Geochimica et Cosmochimica Acta 73:1539-47. 
Park G, Kim JC, Youn M, Yun C, Kang J, Song Y-M, Song S, Noh H-J, Kim D-K, Im H-J. 2010. Dating the Bibong-ri Neolithic site in Korea: excavating the oldest ancient boat. Nuclear Instruments and Methods in Physics Research B 268:1003-7.

Park JH, Kim JC, Cheoun MK, Kim IC, Youn M, Liu YH, Kim ES. 2002. ${ }^{14} \mathrm{C}$ level at Mt. Chiak and Mt. Kyeryong in Korea. Radiocarbon 44(2):559-66.

Pazdur A, Nakamura T, Pawełczyk S, Pawlyta J, Piotrowska N, Rakowski, Sensuła B, Szczepanek M. 2007. Carbon isotopes in tree rings: climate and the Suess effect interferences in the last 400 years. Radiocarbon 49(2):775-88.

Rinn F. 1996. TSAP Version 3.0. Reference Manual. Heidelberg, Germany.
Sano M, Buckley BM, Sweda T. 2009. Tree-ring based hydroclimate reconstruction over northern Vietnam from Fokienia hodginsii: eighteenth century mega-drought and tropical Pacific influence. Climate Dynamics 33:331-40.

Wada Y. 1917. Chosen Kodai Kansoku Kiroku Chosa Hokoku (Reports on the Survey of the Ancient Records of Observation in Korea). Incheon Weather Observatory, Chosen Government General, Il-Han Print Cooperation.

Yoo C, Park M, Kim HJ, Choi J, Sin J, Jun C. 2015. Classification and evaluation of the documentaryrecorded storm events in the Annals of the Choson Dynasty. Journal of Hydrology 520:387-96.

YTN. 2010. YTN news. URL: <http://www.ytn.co.kr>. 